\author{
Iwona Gibas and Helena Janik
}

\title{
REVIEW: SYNTHETIC POLYMER HYDROGELS FOR BIOMEDICAL APPLICATIONS
}

\author{
Gdansk University of Technology, Chemical Faculty, Polymer Technology Department, \\ 80-233 Gdansk, ul Narutowicza 11/ 12; \\ iwonagibas@urethan.chem.pg.gda.pl; janik@urethan.chem.pg.gda.pl
}

Received: August 28, 2010 /Revised: August 30, 2010 / Accepted: October 7, 2010

(c) Gibas I., Janik H., 2010

\begin{abstract}
Synthetic polymer hydrogels constitute a group of materials, used in numerous biomedical disciplines, and are still developing for new promising applications. The aim of this study is to review information about well known and the newest hydrogels, show the importance of water uptake and cross-linking type and classify them in accordance with their chemical structure.
\end{abstract}

Keywords: polymer, hydrogel, biomaterial, biomedical polymer, polymer hydrogel.

\section{Introduction}

Polymer hydrogels are a still new, rapidly developing group of materials, gaining wide application in many fields, especially pharmacy, medicine and agriculture. Since the 1970s many reports have been published in the scientific literature about new chemical and physical structures, properties and innovative restricted applications of polymer hydrogels. The aim of this review paper is to gather and systemize all this information, providing a clear classification of synthetic polymer hydrogels in accordance with their chemical structure.

\section{$\mathrm{H}$ istory of $\mathrm{H}$ ydrogels}

For over fifty years hydrogels have been used in numerous biomedical disciplines, in ophthalmology as contact lenses and in surgery as absorbable sutures, as well as in many other areas of clinical practice to cure such illnesses as diabetes mellitus, osteoporosis, asthma, heart diseases and neoplasms. It was in 1955 that Professors Lim and Wichterle of Prague, Czech Republic, synthesized the first hydrogel with potential biomedical uses. That was synthetic poly-2-hydroxyethyl methacrylate, used - soon after its discovery - in contact lens production [1-4]. The main advantage of that revolutionary biomaterial was its stability under varying
$\mathrm{pH}$, temperature and tonicity conditions. In the $1980 \mathrm{~s}$ hydrogels were modified for other applications. Lim and Sun obtained calcium alginate microcapsules for cell engineering, and Yannas' group modified synthetic hydrogels with some natural substances, such as collagen and shark cartilage to obtain novel dressings, providing optimal conditions for healing burns. Nowadays, hydrogels continue to interest scientists. They are obtained from new materials using the latest techniques to make them safe and non-toxic. The final hydrogel product is present in very advanced applications, e.g. tissue engineering and regeneration, where they can be applied in a non-invasive manner. They can serve in the prevention of thrombosis, post-operative adhesion formation, drug delivery systems, coatings for biosensors and cell transplantation [5-9].

\section{What are Hydrogels?}

According to the latest medical and pharmaceutical encyclopaedias, there is still no precise and limiting definition of the term hydrogel. Most often, a hydrogel is considered to be a material made when a water-insoluble polymer absorbs a large amount of water, or else it is simply a water-swollen polymer network $[4,10]$. Polymer hydrogels can be of either synthetic or natural origin, homopolymers or copolymers [11]. According to another definition by Hoffman [3], the hydrogel is a permanent or chemical gel stabilized by covalently cross-linked networks. These chemical hydrogels may be prepared either by crosslinking water-soluble polymers or by converting hydrophobic polymers into hydrophilic polymers that are then cross-linked to form a network. With such a structure, hydrogels are able to swell, absorbing a large amount of water without the polymer dissolving, which gives them characteristics similar to those of soft tissue. Although the water content in hydrogels may be as little as a few percents or as much as over $99 \%$, hydrogels retain the properties of solids [11, 12]. Advanced hydrogel materials can begin 
to swell under certain favourable conditions and respond to the presence of stimuli; such hydrogels are called environment-sensitive or stimuli sensitive [13].

\section{Cross-linking in Hydrogels}

Hydrogels do not disintegrate during swelling thanks to their cross-linked structure. Cross-linking may be either physical (e.g. hydrogen bonding) or chemical (covalent, atomic, ionic). The cross-linking may take place in two environments: in vitro during the preparation of a hydrogel, or in vivo (in situ) after application in a precise location of the human body.

To initiate chemical cross-linking it is necessary to introduce into the reaction mixture a low-molecular-weight cross-linking agent together with a polymer; the hyaluronic acid (HA) hydrogels prepared by Hahn et al. [14], for example, were chemically cross-linked with covalent bonds formed by bis(sulphosuccinimidyl) (BS $\left.{ }^{3}\right)$. In this case, once the polymer had been dissolved in water and was precipitated with ethanol, $\mathrm{BS}^{3}$ was dissolved in water and added in the requisite amount. The cross-linking reaction took place within an hour at $310 \mathrm{~K}$. Another example is the cross-linked methyl methacrylate-co-itaconic acid (MMA-co-IA) hydrogel used for drug delivery and drug release. This hydrogel was prepared by free radical copolymerization of methyl methacrylate (MMA) with itaconic acid (IA) (dissolved in ethanol) using two crosslinkers - ethylene glycol dimethacrylate (EGDMA) and N,N methylene bisacrylamide (MBAA) - with benzoyl peroxide as the initiator (dissolved in MMA) $[15,16]$.

The usual technique for cross-linking a hydrogel in vivo (in situ) is photopolymerization. The aim of this kind of cross-linking is to inject a polymer mixture, and the liquid-to-solid transformation into a three-dimensional network takes place when the cross-linker appears (usually laser exposure, $514 \mathrm{~nm}$ ). This method is utilized in dentistry to form sealants and dental restorations in situ, in angioplasty and orthopaedics. There are several advantages of photopolymerization over traditional techniques: spatial and temporal control of polymerization, fast curing rates at physiological temperatures and minimal heat production. The biggest advantage of photopolymerization is its noninvasiveness (using laparoscopic devices, catheters, subcutaneous injection with transdermal illumination) in contrast to traditional surgery, which minimizes the risk to patients' health $[5,10,12]$.

\section{W ater in H ydrogels}

Water in hydrogels not only provides a moist environment (important, for example, in wound healing) but also controls the permeation of nutrients into the cells and of cellular products out of the hydrogels. Dried hydrogels can swell in water or saline up to 1000 times their own weight [17]. The amount of absorbed water is usually expressed as the equilibrium water content-EWC (Eq. 1):

$$
E W C=\frac{W_{w}}{W_{t}} \cdot 100 \%
$$

where $W_{w}$ is the weight of water in the gel and $W_{t}$ is the total weight of the hydrated gel.

EWC is the most significant property of hydrogels, since the water in a hydrogel structure lends them unique properties and potential further applications in biomedical fields [10].

The swelling of hydrogels is quite a complicated process and consists of a number of steps. In the first step, water molecules entering the hydrogel matrix hydrate the most polar, hydrophilic groups. This results in the appearance of primary bound water. In the second step, hydrophobic groups are exposed, and they interact with water molecules giving so-called hydrophobically bound water or secondary bound water. Primary and secondary bound water together form total bound water. In the third step, because the osmotic driving force of the network towards infinite dilution is resisted by the covalent or physical cross-links, an additional amount of water is absorbed. The water absorbed up to the equilibrium swelling level is called bulk water or free water; it fills the space between the network chains and the centres of larger pores, macropores or voids [3].

The total amount of water absorbed by a hydrogel depends on the temperature and the specific interaction between water molecules and polymer chains; it can be described by the Flory-Huggins solution theory. The free energy of the mixing $(\Delta G m)$ of polymer chains and water molecules is expressed by Eq.

$$
\Delta G m=k T\left[n_{w} \ln \phi_{w}+\ln \left(1-\phi_{w}\right)+\chi n_{w}\left(1-\phi_{w}\right)\right]
$$

where: $\chi$ is the apparent interaction (water moleculespolymer) parameter dependent on chemical structure, which can be calculated from experimental data of the equilibrium water uptake of the network in the presence of a vapour phase containing water, $n_{w}$ is the number of molecules, and $\phi_{w}$ is the water volume $[18,19]$.

The literature reports a number of classifications of hydrogels, and several different points of view are presented. Depending on the presence of a charge on the bound groups, hydrogels can be either ionic (anionic or cationic) or neutral. The type of cross-linking agent can be the criterion for classification: hydrogels can be physical or chemical. It is also common to divide hydrogels into groups by structure: amorphous, semicrystalline, bound by oxygen molecules, with a supermolecular structure, or hydrocolloidal aggregations. Nowadays, hydrogel nanocomposites with mechanical properties superior to 
those of traditional hydrogels are becoming popular. Very often groups of polymer hydrogels for specific applications are discussed. The more advanced the application, the more complicated the description of the materials.

In this review paper, hydrogel groups are presented with their modifications and possible applications in accordance with their chemical structure.

\section{Poly(hydroxyethyl methacrylate)}

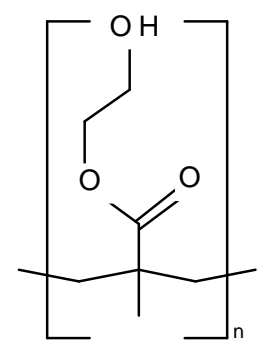

Fig. 1. PolyHEMA structure

Known for many years, poly(hydroxyethyl methacrylate) (polyHEMA, PHEMA) (Fig. 1) is one of the most important and most widely applied hydrogel biomaterials. Since 1955 it has been modified with many natural and synthetic substances and by various methods, and has been applied in the production of contact lenses and dressings, and for drug delivery and tissue engineering purposes. The properties of polyHEMA depend, among other things, on the method of synthesis, polymer content, degree of cross-linking, temperature and final application environment. The synthesis can be carried out with simultaneous cross-linking by UV-radiation. In one possible way of preparing polyHEMA [20] 2-hydroxyethyl methacrylate (HEMA) as a monomer, polyethylene glycol dimethacrylate as the cross-linking agent and benzoin isobutyl ether (BIE) as the UV-sensitive initiator were used. Deionized water (DI) in an amount appropriate to the desired concentration should then be added to the system prepared from the listed components. The final products are obtained in the form of films or membranes by treating them with $\mathrm{UV}$ radiation (4 lamps, $20 \mathrm{~W}, \lambda=253.7 \mathrm{~nm}, 11 \mathrm{~mm}$ distance from the source, $20 \mathrm{~min}$ ). Next, the film is immersed for $24 \mathrm{~h}$ in water until it is fully saturated in order to remove toxic or unreacted substances that could damage a living tissue. Besides contact lenses, pHEMA can be applied in artificial skin manufacturing, dressings, especially burn dressings, as it ensures good wound-healing conditions. It is also used for DDSs as well as for marrow and spinal cord cell regeneration, scaffolds for promoting cell adhesion and in artificial cartilage production [21-28].

Another cross-linking agent used in polyHEMA manufacturing is a low molecular weight 1,1,1-trimethylol propane trimethacrylate. The hydrogel obtained with this agent is soft; it contains $30-40 \%$ of water and is distinguished by its high oxygen permeability. With these properties, it is used mainly in contact lenses and in liquid devices for drainage manufacturing, or for obtaining matrices for drug delivery systems and soft tissue implants. The improvement of these hydrogel mechanical properties could extend its applications. According to some authors such an improvement can be achieved by synthesizing the amphiphilic material or introducing some hydrophobic compounds into its structure [29].

\section{Polyethylene Glycol and Derivatives}

Poly(ethylene glycol) (PEG), otherwise known as poly(oxyethylene) or poly(ethylene oxide) (PEO), is one of the most widely used hydrogels in medicine and biomedicine. Hydrogels based on its derivatives polyethylene glycol methacrylate (PEGMA), polyethylene glycol dimethacrylate (PEGDMA) and polyethylene glycol diacrylate (PEGDA) - are likewise widely applied.

PEG-based hydrogels are characterized by their high biocompatibility, lack of toxic influence on surrounding tissue and solubility in water, which makes them good candidates for drug delivery system applications [30, 31].

PEG hydrogel drug release systems are stimuli sensitive and react in the presence of a physical or chemical

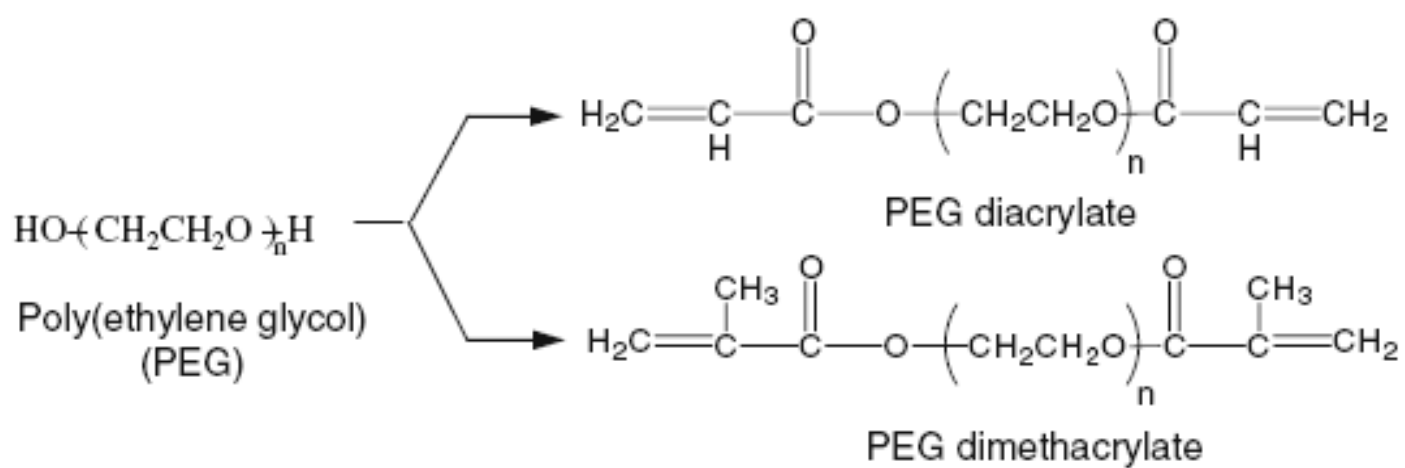

Fig. 2. Polyethylene glycol and its derivatives 
(biological) agent. Because of their unique properties, hydrogels used for these kinds of drug release systems are called "smart" or "intelligent gels". Physical stimuli include temperature, solvent, light, radiation, pressure, a magnetic, acoustic or electrical field, while the chemical and biological stimuli include $\mathrm{pH}$, specific ions, and molecular recognition events [8, 32].

Chemically cross-linked PEG hydrogels are used in the manufacture of synthetic, biologically active hydrogel scaffolds for protein recombination and functional tissue production. But the main field of PEG hydrogel applications is in DDSs, as drug carriers in the efficient and controlled release systems of drugs, proteins and biomolecules, and growth factor distribution [33-36].

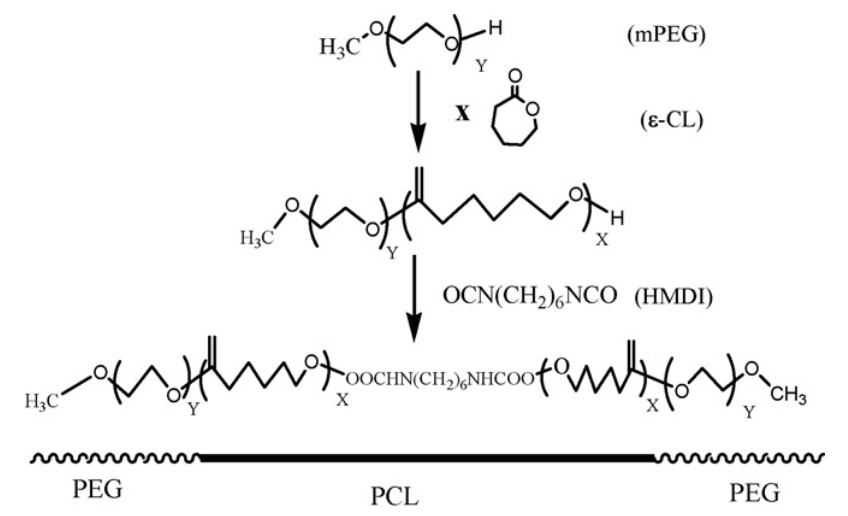

Fig. 3. Scheme of obtaining PECE copolymers for DDSs [34]
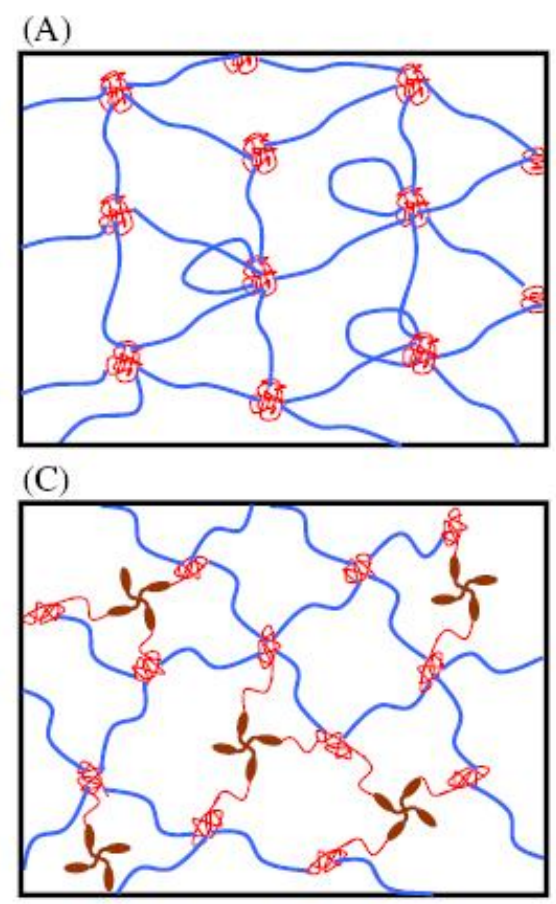

Gong et al. [34] synthesized the biodegradable triblock poly(ethylene glycol)-poly( $\varepsilon$-caprolactone)poly(ethylene glycol) (PEG-PCL-PEG, PECE) hydrogel copolymers for developing drug delivery systems by the ring-opening copolymerization (Fig. 3) of $\varepsilon$-caprolactone. In this synthesis mPEG was used as initiator, stannous octoate as catalyst and HMDI as coupling agent during triblock formation.

According to these authors thermosensitive PECE hydrogels formed in situ can be easily applied in controlled drug delivery, cell encapsulation and tissue repair. In a number of experiments they demonstrated its specific biodegradability ratio and biocompatibility. Both hydrophilic and hydrophobic drugs, as well as protein drugs are released slowly from a PECE hydrogel over a sustained time period. It is an alternative to the commercial Pluronic F-127 hydrogel.

Lin and Anseth [35] discuss strategies for delivering drugs and methods of PEG hydrogel formation, mentioning all the drawbacks involved in PEG incorporation. To their knowledge PEG hydrogels provide a unique niche for cell encapsulation, as they are highly biocompatible with cells under appropriate polymerization conditions. PEG hydrogels are used as matrices for controlling drug delivery and as cell delivery vehicles for promoting tissue regeneration. The scheme of the PEG structures resulting in the most common types of polymerization is presented in Fig. 4. These authors draw attention to a new method of PEG hydrogel formation, called "Click" chemistry. This strategy, based on a step-growth mechanism, is
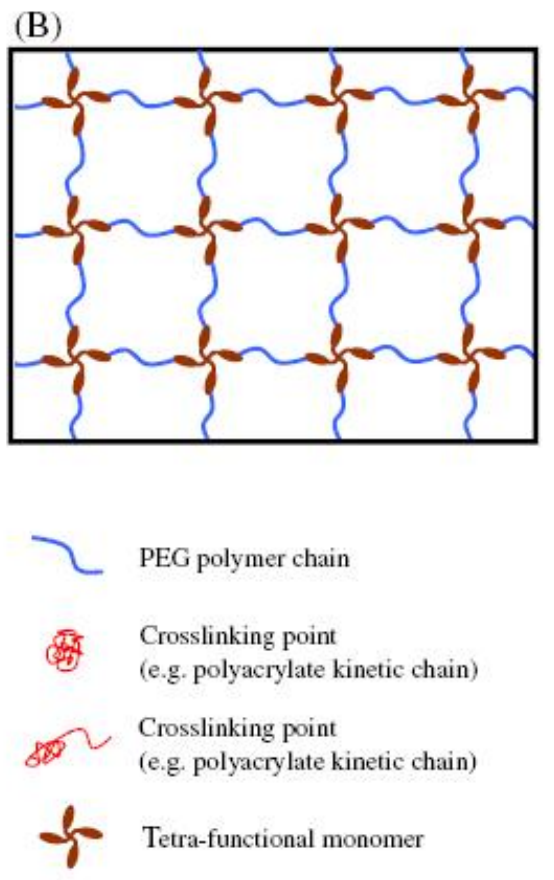

Fig. 4. Structures of PEG hydrogels formed during different kinds of polymerization via: chain-growth (a), step-growth (b) and mixed mode - step and chain polymerization (c) 
distinguished by its rapid and specific reaction, as well as versatility with respect to bioconjugation. In this typical reaction scheme, macromers bearing azide and alkyne functional groups are "clicked" together in the presence of catalysts to form stable covalent linkages. This method produces PEG hydrogels with good mechanical properties and permits independent control of the physical and chemical properties of the PEG hydrogels.

Another type of PEG-based hydrogel for DDSs is presented in the work of Kim et al. [36]. They prepared copolymers of methacrylic acid (MAA) with a mixture of PEG-PEGMA in a free-radical photopolymerization using tetra(ethylene glycol) dimethacrylate as cross-linker. The cross-linking occurred in the presence of an initiator - 1-hydroxycyclohexyl phenyl ketone - under a nitrogen atmosphere during a 30-minute exposure to UV light. The authors claim that the swelling behaviour and consequently the rate of release strongly depend on the molecular weight of PEG. These hydrogels were successfully used in insulin release systems.

Lee et al. [37] describe PEGDA hydrogels modified with $\beta$-chitosan, which is interesting owing to possible biocompatibility improvement of the hydrogel. The hydrogel is obtained by adding a $10 \%$ aqueous solution of PEGDA to a $2 \%$ solution of chitosan in the acetic acid. The hydrogel is cross-linked by UV radiation. The final product displays an IPN structure and contains 77-83\% of water.

PEG and PEGMA hydrogels, like polyvinyl alcohol (described below), can be applied in tissue engineering purposes for cartilage reconstruction. Riley et al. [38] obtained this kind of hydrogel by the addition of PEG to PEGMA and dissolution of the mixture in the phosphate buffered saline (PBS) with the gentamycin sulphate. All reagents were exposed to $U V$ radiation $(\lambda=365 \mathrm{~nm}$, $3 \mathrm{~mW} / \mathrm{cm}^{2}, 3-5 \mathrm{~min}$ ) in the presence of a photoinitiator 1-cyclohexyl-phenyl-ketone.

\section{Poly(vinyl alcohol)}<smiles>CC(C)(C)CC(O)C1CC1</smiles>

Fig. 5. Poly(vinyl alcohol) structure

Beyond the advantages of typical hydrogel materials (ability to absorb water, gas permeability, soft tissue imitation, flexibility and biocompatibility), polyvinyl alcohol (PVA)-based hydrogels are distinguished by their good mechanical properties and the ability to retain water in the structure, which ensures a prolonged moist environment. On removal from water, poly(HEMA) hydrogels can evaporate unbound water, retaining only a small amount of moisture. PVA hydrogels are used in contact lens production, cartilage reconstruction and regeneration, artificial organs, drugs systems and wound dressings, providing the humid environment beneficial for wound healing [38, 39].

A wound dressing providing the proper level of humidity halves the healing time in comparison to a traditional dressing, which may dry and irritate the damaged skin. This was mentioned by Winter in 1962 [40] and is confirmed by the latest knowledge [41, 42]. Wound care materials providing the skin with a moist environment, favour epithelial cell and tissue reconstruction and make a change of dressing less harmful.

PVA hydrogels can be obtained by alternating cycles of freezing and thawing. The PVA material prepared by this method has a greater mechanical strength than that obtained using UV radiation as the cross-linking agent [43, 44]. Also, functional groups in PVA are more accessible than in the PEG structure, which broadens its range of application. However, obtaining PVA/ PEG copolymers with different proportions can control the rate and level of degradation: a higher content of PEG blocks reduces the time of hydrogel degradation [45].

An interesting PVA hydrogel modification was proposed by some authors [45-47]. Hydroxyapatite nanoparticles were introduced into the structure yielding a hydrogel with high adhesion to the living tissue. Thanks to its good biocompatibility and lack of thrombogenicity it is applicable as bone defect and cartilage filler. The method involves the preparation of particles of hydroxyapatite from $\mathrm{Ca}(\mathrm{OH})_{2}$ and $\mathrm{H}_{3} \mathrm{PO}_{4}$, the addition of PVA with simultaneous heating and mixing for a few hours $(9 \mathrm{~h} / 363 \mathrm{~K}$ [46]) and exposure to freezing/thawing cycles $(253 \mathrm{~K} / 14 \mathrm{~h}$ and RT/4 h) to initiate crystallization and cross-linking [46-48].

Cascone et al. [49] describe the synthesis of modified PVA hydrogel for tissue engineering processes. A $10 \%$ aqueous solution of PVA was exposed to a high temperature in an autoclave $\left(120^{\circ} \mathrm{h} / 1 \mathrm{~h}\right)$ and filled with a suitable amount of the modifier such as gelatin, dextrin, hyaluronic acid (HA), collagen, dextrane (Dx) or chitosan. The mixture was then subjected to eight cycles of freezing $(253 \mathrm{~K} / 1 \mathrm{~h})$ and thawing (RT/30 min). Their hydrogels are intended to work in DDSs or as matrices and scaffolds in tissue engineering.

A PVA hydrogel designed as a drug carrier was prepared by Alemzadeh et al. [50] by dissolving PVA powder in DI water and heating at $363 \mathrm{~K}$ for $9 \mathrm{~h}$. Sulphuric acid was used as a catalyst, $10 \%$ acetic acid as a buffer, $50 \%$ methanol as a quencher and glutaraldehyde as a cross-linker. The mixture was then centrifuged (105 rpm), applied to glass plates and left for $48 \mathrm{~h}$ at 298-303 K.

Another field of PVA hydrogel applications encompasses injectable implants, endoprostheses or soft tissue fillers in plastic, reconstructive and aesthetic surgery. Non-modified PVA does not adhere to cells or proteins, which makes it attractive for new tissue engineering purposes [45, 51-54]. 


\section{Polyvinylpyrrolidone}

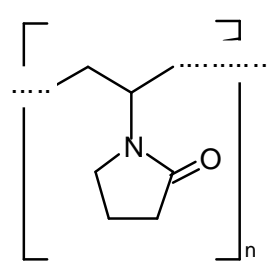

Fig. 6. Polyvinylpyrrolidone structure

Next to PVA hydrogels, another group widely used in biomedical applications is hydrogels based on polyvinylpyrrolidone (PVP). They are present in DDSs and wound dressings and are usually obtained with the radiation technique, an apparently simple, efficient, clean and environmentally friendly process. The application of radiation in the formation of hydrogels for biomedical use offers a unique opportunity to combine the formation and sterilization of a product in one single technological step. PVP hydrogels can thus be regarded as advantageous owing to their simple formation and lower production costs, softness and elasticity; their ability to store large amounts of liquid while retaining quite good mechanical properties makes them optimal candidates for the manufacture of dressings. To improve its mechanical properties PVP is usually blended with other polymers (mainly natural), which also enhances its biocompatibility and water uptake. Agar, cellulose or PEG are the usual polymers added [55-57].

Many authors discuss examples of PVP hydrogels obtained with the radiation technique for wound healing applications. Benamer et al. [55] prepared PVP solutions and carried out the irradiation using a ${ }^{60} \mathrm{Co}$ source at a dose rate of $3.2 \mathrm{~Gy} / \mathrm{min}$. Lugao et al. [58] obtained PVP hydrogels using different irradiation doses (5-15 KGy) and different additives: PEG (MW 600, 6000), PEO (400000) and glycerol. According to these authors, glycol and PEO used as additives reduce the cross-linking density of the PVP network, whereas PEG is non-toxic and increases the elasticity of the gels as a result of the plasticizing effect. Moreover, PVP/PEG hydrogels are sterile and noncytotoxic, which makes PEG an ideal addition to biomedical hydrogels designed as dressings. Ajji et al. [56] discuss the influence of additives and the radiation technique. They state that agar enhances the mechanical properties but also facilitates the penetration of microorganisms, especially in a moist environment. In their paper they describe the preparation of hydrogels consisting of PVP, PEG and agar. The authors conclude that these hydrogels meet the requirements of hydrogel wound dressings and that their properties can be controlled by the PVP and PEG content and by the irradiation dose. By changing these parameters it is even possible to obtain a dressing material that is a good barrier against microbes.

Wang et al. [57] continue the discussion about additives to PVP hydrogels. They suggest using cellulose or carboxymethyl cellulose (CMC) instead of agar. CMC has a good water solubility, biocompatibility, a high abundance and a low cost. Blending PVP and CMC yields a hydrogel with good mechanical properties (mechanical strength better than that of pure CMC and flexibility superior to that of pure PVP hydrogels), high water uptake, enhanced biodegradability, and the non-noxious quality expected from a perfect hydrogel dressing.

Can et al. [59] obtained hydrogels from two systems: $6 \%$ PVP solution in DI water and the same but with added $4 \% \mathrm{~K}_{2} \mathrm{~S}_{2} \mathrm{O}_{8}$. PVP/ $\mathrm{K}_{2} \mathrm{~S}_{2} \mathrm{O}_{8}$ hydrogels have a higher swelling rate, uptake capacity and a more efficient penetration of BSA solution into the hydrogel system than in PVP hydrogels. This implies biocompatibility with biochemical systems and suitability for drug release purposes as well as protein separation from plasma.

\section{Polyimide}

Like PVA hydrogels, polyimide (PI) hydrogels are used mainly in plastic and reconstructive surgery. They can imitate soft tissue, contain a great amount of water, have the required mechanical strength and a high level of biocompatibility. They are soft, transparent and have good permeability - oxygen passes through them especially easily.

An example is the polyalkylimide (PAI) hydrogel containing $96 \%$ of water. It is a polyacrylate gel containing alkylimide and amide groups in its structure. It is commonly applied in a form of an injectable endoprosthesis suitable for the simple non-invasive correction of tiny imperfections [60].

\section{Polyacrylate}

Polyacrylate (PA) hydrogels, mainly polyacrylamide (PAA), are used in many branches of industry, most commonly as agricultural gels. They also play an important role in biomedical applications in aesthetic corrections, as soft tissue fillers and augmentation materials. Besides silicone, PAA topped the list of applications in breast augmentation in Eastern Europe and Asia. Despite its high biocompatibility, however, after some years breast implants caused tissue and post-reactive complications, e.g. granular tissue or inflammations [61].

A good example of a commonly used PAA hydrogel is Aquamid [62-64], a commercially available homogeneous hydrogel containing $2.5 \%$ of PAA and $97.5 \%$ of water; it is stable in the natural environment, is non-degradable, and has optimal viscosity and elasticity properties. As an endoprosthesis, it was designed to be non-toxic, noninflammatory, and to imitate surrounding soft tissue.

\section{Polyurethane}

Recent years have witnessed an upsurge in interest in polyurethane (PU) hydrogels. The specificity of PU hydrogels 
is based on their wide variety of final product properties depending on their chemical structure and monomers, which also makes for extensive bio-applications.

It is important to choose the proper oligodiols (commonly used PEG or poly( $\varepsilon$-caprolactonediol) (PCL)), which will determine the hydrogel properties and molar ratio of $\mathrm{NCO} /$ $\mathrm{OH}$ groups [65]. Petrini et al. [66] obtained a PU hydrogel using PEG with a molar weight of 1500-3000, after drying and dehydration $(353 \mathrm{~K} / 6 \mathrm{~h})$. The PUs were obtained in a one-step bulk synthesis using 1,6-hexamethylene diisocyanate (HDI) or methylene bis-(4-cyclohexy-lisocyanate) (HMDI) and 1,4-butanediol or maleic acid as a chain extender with the $0.02-0.05$ wt $\%$ addition of a dibutyltin dilaurate or $\mathrm{FeCl}_{3}$ catalyst. The reaction occurs within a few minutes, after which the mixture is placed in a propylene cube at $368 \mathrm{~K}$ for $20 \mathrm{~h}$ to finish the process. The final product can be also obtained in the form of films, using $5 \%$ solution of polymer in methanol [67].

PU hydrogels are applied as drug carriers, in DDS, in wound dressing manufacture, artificial kidney membranes, catheter coating materials and contact lenses [68-70].

To extend the spectrum of application of PU hydrogels they can be modified in many ways. For example, when obtaining the IPN hydrogel PU/PAA, the water absorption can be controlled. This kind of synthesis was described by Kim et al. [69], where PU and PAA were simultaneously obtained from PEG and acrylic acid respectively. Then PU and PAA were mixed, and the respective cross-linking agents vinylpyrrolidone and methylenebisacrylamide added, after which the mixtures were exposed to UV radiation. This type of PU hydrogel is used for dressings, DDS, artificial muscles, sensor systems and bioseparators.

Kazmierska et al. [71] proposed a novel hydrogel system consisting of an interpolymer of PU and PVP to serve as a drug reservoir for local drug delivery. With the composition of a hydrophilic matrix with a hydrophobic drug, an optimal drug release profile is easily obtained owing to the hydrogel excellent swelling behaviour in DDSs.

The very interesting biodegradable PU have recently been obtained with the use of synthetic a-PHB (polyhydrobutyrate) [72] or with the use of different hard segment content [73].

\section{Conclusions}

Synthetic polymer hydrogels differ in their characteristics due to various chemical structure, synthesis technique, water content or cross-linking. It is still possible to design new hydrogel fulfilling specific functions for specific needs. A change in chemical composition, or even a change in one of the synthesis factors (cross-linking method, cross-linking agent, synthesis method, conditions of the synthesis) may lead to new intelligent biomaterials.

\section{References}

[1] Nierzwicki W. and Prins W.: J. Appl. Polym. Sci., 1975, 19, 1885.

[2] Wichterle O. and Lim D.: Nature, 1960, 185, 117.

[3] Hoffman A.: Adv. Drug Deliv. Rev., 2002, 43, 3.

[4] Swarbrick J. (Ed.): Encyclopedia of Pharmaceutical Technology, 3rd edn. Informa Healthcare, New York 2006.

[5] Nguyen K. and West J.: Biomaterials, 2002, 23, 4307.

[6] Peppas N. and Bures P.: Eur. J. Pharm. Biopharm., 2000, 50, 27.

[7] Sawhney A. and Pathak C.: J. Biomed. Mat. Res., 1994, 28, 831.

[8] Miyata T., Uragami T. and Nakamae K.: Adv. Drug Deliv. Rev., 2002, 54, 79.

[9] Chang C., Duan B., Cai J. and Zhang L.: Eur. Polym. J., 2010, 46, 92.

[10] Williams D. (Ed.): Concise Encyclopedia of Medical \& Dental Materials, Pergamon Press, Oxford 1990.

[11] Langer R. and Peppas N.: Bioeng., Food \& Nat. Prod., 2003, 49, 2990.

[12] Truong N. and West J.: Biomaterials, 2002, 23, 4307.

[13] Qiu Y. and Park K.: Adv. Drug Deliv. Rev., 2001, 53, 321.

[14] Hahn S., Park J., Tomimatsu T. and Shimoboji T.: Int. J. Biolog. Macromol., 2007, 40, 374.

[15] Ranjha N., Mudassir J. and Akhtar N.: J. Sol-Gel Sci. Techn., 2008, 47, 23.

[16] Mudassir M. and Ranjha N.: J. Polym. Res., 2008, 15, 195.

[17] Glados S. and Maciejewski M.: Wiadomosci Chemiczne, 1998, 52, 101.

[18] Pradas M., Gomez Ribelles J., Serrano Aroca A. et al.: Colloid Polym. Sci., 2001, 279, 323.

[19] Ferrer G., Pradas M., Gomez Ribelles J. and Sanchez M.: Polymer, 2004, 45, 6207.

[20] Young C., Wu J-R. and Tsou T-L.: J. Membrane Sci., 1998, 146, 83.

[21] Sykovra E., Jendelovra P.,Urdzrэkovra L. et al.: Cellular \& Molecular Neurobiology, 2006, 26, 7.

[22] Kuo S., Liou C., Chang S. and Wang Y.-J.: J. Polym. Res., $2001,83,169$.

[23] Pavlyuchenko V., Ushakov N., Novikov S. et al.: Rus. J. Appl. Chem., 2006, 79, 584.

[24] Saika S., Miyamoto T. and Ohnishi Y.: J. Cataract. Refract. Surg., 2003, 29, 1198.

[25] Kubinova S., Horak D., Kozubenko N. et al.: Biomaterials, 2010,31, 5966.

[26] Kubinova S, Horak D. and Sykova E.: Biomaterials, 2009, 30, 4601.

[27] Kumar N., Ganapathy H., Kim J. et al.: Eur. Polym. J., 2008, 44, 579 .

[28] Bavaresco V., Zavaglia C., Reis M. and Gomes J.: Wear, 2008, 265, 269.

[29] Cretu A., Gattin R., Brachais L. and Barbier-Baudry D.: Polym. Degradation \& Stability, 2004, 83, 399.

[30] Zhao X. and Harris M.: J. Pharmac. Sci., 1998, 87, 1450.

[31] Underhill G., Chen A., Albrecht D. and Bhatia S.: Biomaterials, 2007, 28, 256. 
[32] Chao G., Den H., Huang Q. et al.: J. Polym. Res., 2006, 13, 349. [33] Rizzi S., Halstenberg S. and Hubbell J.: Eur. Cells and Mat., 2001, 2, 82.

[34] Gong C., Shi S., Dong P-W., et al.: Int. J. Pharmaceutics, 2009, 365, 89.

[35] Lin C. and Anseth K.: Pharmac. Res., 2008, 26, 631.

[36] Kim B. and Peppas N.: Biomed. Microdevices, 2003, 5, 333.

[37] Lee Y., Kim S.S. and Kim S.H.: J. Mat. Sci.: Mat. in Medicine, 1997, 8, 537.

[38] Riley S., Dutt S., de la Torre R. et al.: J. Mat. Sci.: Mat. in Medicine, 2001, 12, 983.

[39] Bandera V., Hudson D., de Wet P. et al.: Burns, 2000, 26, 265.

[40] Petkow L. and Gorkiewicz- Petkow A.: Przeglad Flebologiczny, 2002, 10, 101.

[41] Wu M., Bao B., Yoshii F. and Makuuchi K.: J. Radioanal. Nuclear Chem., 2001, 250, 391.

[42] Ovington L.: Clinics in Dermatology, 2007, 25, 33.

[43] Muratoqlu O., Spiegelberg S., Ruberti J. and Abt Niels.: Pat. WO/2006/040128, Publ. April 20, 2006.

[44] Wu M., Bao B., Yoshii F. and Makuuchi K.: J. Radioanal. Nuclear Chem., 2001, 250, 391.

[45] Lum L. and Elisseeff J.: Ch. 4 [in:] Ashammakhi N. and Ferretti P. (Eds.) Topics in Tissue Engineering. University of Oulu, Oulu 2003.

[46] Yusong P., Dangsheng X. and Xiaolin C.: J. Mater. Sci., 2007, 42, 5129.

[47] Fenglan X., Yubao L., Xuejiang W. et al.: J. Mater. Sci., 2004, 39, 5669.

[48] Willcox P., Howie D., Schmidt-Rohr K. et al.: J. Polym. Sci. B, 1999, 37, 3438.

[49] Cascone M., Lazzeri L., Sparvoli E. et al.: J. Mater. Sci.: Mater. in Medicine, 2004, 15, 1309.

[50] Alemzadeh J. and Vossoughi M.: Chem. Eng. Proc., 2002, 41, 707.

[51] Muratoglu OK, Spiegelberg SH, Ruberti JW and Abt Niels.: App. 20040171740, Publ. April 13, 2006.

[52] Goldan O., Georgiou I., Grabov-Nardini G. et al.: Dermatologic Surg., 2007, 33, 199.

[53] Dini L., Panzarini E., Miccoli M. et al.: Tissue \& Cell, 2005, 37, 479.

[54] Li J., Wang N. and Wu X.: J. Control. Release, 1998, 56, 117. [55] Benamer S., Mahlous M., Boukrif A. et al.: Nucl. Instrum. \& Methods in Phys. Res. B, 2006, 248, 284.

[56] Ajji Z., Othoman I. and Rosiak J.: Nucl. Instrum. \& Methods in Phys. Res. B, 2005, 229, 375.
[57] Wang M., Xu L., Hu H. et al.: Nucl. Instrum. \& Methods in Phys. Res. B, 2007, 265, 385.

[58] Lugao A., Rogero S. and Malmonge S.: Rad. Phys. \& Chem., 2002, 63, 543.

[59] Kaplan Can H., Kirci Denizli B., Kavlak S. and Guner A.: Rad. Phys. \& Chem., 2005, 72, 483.

[60] Ramires P., Miccoli M., Panzarini E. et al.: J. Biomed. Mater. Res. B, 2005, 72B, 230.

[61] Cheng N., Wang Y., Wang J. et al.: Polyacrylamide Gel Aesth. Plast. Surg., 2002, 26, 375.

[62] Novaes W. and Berg A.: Aesth. Plast. Surg., 2003, 27, 376. [63] Christensen L., Breiting V., Vuust J. and Hogdall E.: Eur. J. Plast. Surg., 2006, 28, 464.

[64] Breiting A., Aasted A., Jorgensen A. et al.: Aesthetic Plast. Surg., 2004, 28, 45.

[65] Jiang X., Li J., Ding M. et al.: Eur. Polym. J., 2007, 43, 1838 .

[66] Petrini P., Fare S., Piva A. and Tanzi C.: J. Mater. Sci.: Mater. in Medicine, 2003, 14, 683.

[67] Petrini P. and Tanzi M.: J. Mater. Sci.: Mater. in Medicine, 1999, 10, 635.

[68] Kim S.J., Lee K. and Kim S.I.: React. \& Funct. Polym., 2003, 55, 69.

[69] Abraham G., de Queiroz A. and San Roma J.: Biomaterials, 2001, 22, 1971.

[70] Akita S., Akino K., Imaizumi T. et al.: Burns, 2006, 32, 447. [71] Kazmierska K., Kuc K. and Ciach T: Acta Poloniae Pharmaceutica - Drug Res., 2008, 65, 763.

[72] Brzeska J., Dacko P., Janeczek H. et al.: Polimery, 2010, $\mathbf{5 5}, 42$.

[73] Gibas I. and Janik H.: Polish J. Appl.Chem., 2009, 53, 9.

\section{ОГЛЯД: СИНТЕТИЧНІ ПОЛІМЕРНІ ГІДРОГЕЛІ ДЛЯ БІОМЕДИЧНОГО ЗАСТОСУВАННЯ}

Анотація. Синтетичні полімерні гідрогелі являють собою групу біоматеріалів, які вже використовуються в чисельних біомедичних галузях, $і$ які розробляються для нового перспективного застосування. В роботі проаналізовано інформацію як про відомі, так і новітні гідрогелі. Показано, наскільки важливими є здатність до водопоглинання $і$ тип структурування, а також проведено класифікацію гідрогелів відповідно до їх хімічної структури.

Ключові слова: полімер, гідрогель, біоматеріал, біомедичний полімер, полімерний гідрогель. 